\title{
Informing Management Strategies for a Reserve: Results from a Discrete
}

\section{Choice Experiment Survey}

\author{
Bui Bich Xuan ${ }^{a, b, *}$, Erlend Dancke Sandorf ${ }^{c}$ and Margrethe Aanesen $^{a}$ \\ ${ }^{a}$ Norwegian College of Fishery Science, University of Troms $\phi$ The Arctic University of \\ Norway, 9037 Troms $\phi$, Norway. \\ ${ }^{b}$ The Faculty of Economics, Nha Trang University, 02 Nguyen Dinh Chieu, Nha Trang, \\ Vietnam. \\ ${ }^{c}$ Centre for Environmental and Resource Economics, Swedish University of Agricultural \\ Sciences, 90183 Umeå, Sweden. \\ * Corresponding author. \\ Email address: xuanbb@ntu.edu.vn (B.B.Xuan).
}

\begin{abstract}
It is well-known that operating within the boundaries of a national park provides commercial actors with the opportunity to charge a price premium, though this has to a lesser degree been demonstrated for marine protected areas. We estimate national tourists' willingness-to-pay a price premium for boat trips in the Nha Trang Bay Marine Protected Are, Vietnam, using a discrete choice experiment. Our results show that tourists are willing to pay an average price premium of 18 USD per trip for a large improvement in environmental quality, and that avoiding the loss of jobs for local fishermen is of minor importance. Furthermore, the economic benefits generated from management scenarios that combine biodiversity restoration and environmental quality improvement within the reserve sufficient to cover additional costs of such improvements.
\end{abstract}

KEYWORDS: Marine Protected Areas, Discrete Choice Experiment, Non-market Valuation. 


\section{Introduction}

Marine protected areas (MPAs) may be established to protect biodiversity, sustainably manage fisheries, and develop non-extractive uses of the area, e.g. in the form of "eco-tourism" (Alban et al. 2008). The first two objectives are broadly studied in the literature, and MPAs have been shown to be an appropriate management tool for biodiversity conservation (Halpern 2003; Halpern et al. 2009) and sustainable fisheries (Sanchirico et al. 2006; Schnier 2005b; Schnier 2005a), the latter is, however, still debated. Development of non-extractive activities is often regarded as less important and has therefore received less attention (Alban et al. 2008).

Although the number of MPAs worldwide have increased substantially, from $0.9 \%$ to $8.4 \%$ of areas under national jurisdiction in the period 1990 - 2014 (Juffe-Bignoli et al. 2014), data suggests that only $20-30 \%$ of MPAs are effectively managed, with the remaining being regarded as "paper parks" (Depondt \& Green 2006). The most important obstacle to the success of MPAs is the lack of funding for management (Depondt \& Green 2006). Running an MPA is costly and funding often comes from limited public budgets. Maintaining biological diversity and environmental quality, not to mention making improvements, is challenging. Consequently, how to get a sustainable financial source to cover maintenance of an MPA is a highly relevant question, and especially in developing countries.

It is well known that the use of terrestrial protected areas (national parks) for non-extractive commercial activities, such as eco-tourism, yields a price-premium due to the status of the area as especially serene (Jacobsen \& Thorsen 2010). Some studies underline the attractiveness of MPAs for tourists such as coral reefs, biodiversity, sea mammals, and water quality (Bosetti \& Pearce 2003; Can \& Alp 2012; Madani et al. 2013; Schuhmann et al. 2013; Parsons \& Thur 2008; Wallmo \& Edwards 2008). Authors show that tourists are willing to pay more than the current fees for improved biodiversity and environmental quality within MPAs, and it has been 
demonstrated that "eco-tourism" can serve as a source of funding for the management of MPAs (Depondt \& Green 2006; Madani et al. 2013).

While the development of MPA-based tourism may increase revenues in the local economy, it may at the same time lead to potential conflicts of interest between tourists and local fishers ( Bosetti \& Pearce 2003; Milazzo et al. 2002; Ngoc \& Flaaten 2010; Lee \& Iwasa 2011). In the short-term, fishermen may oppose expanding the MPA for tourism development for fear of losing their jobs due to unavailable fishing grounds, reduced harvest due to smaller fishing grounds, and increased harvesting costs due to having to go further for available fishing grounds. On the other hand, in the long-term, local fishers may benefit from MPA creation or expansion due to positive spillover effects from the MPA to nearby fishing areas, as suggested in the literature (Sanchirico et al. 2005; Sanchirico \& Wilen 2001).

In this paper, we use the Nha Trang Bay marine protected area (NTB MPA) in Vietnam as the empirical background. The objective of the NTB MPA is "to enable local island communities to improve their livelihoods and, in partnership with other stakeholders, effectively protect and sustainably manage the marine biodiversity at NTB as a model for collaborative MPA management in Vietnam" (Dung, 2009). However, after one decade of protection, the recovery of biodiversity within the NTB MPA was very low, including both improvements and deteriorations (Tuan 2011).

Insufficient funds for monitoring and enforcement of the protection regulations are presumed to be contributing factors (Van 2013). Currently, the annual management cost of the NTB MPA is 150,000 USD. User fees levied on tourists visiting Mun Island, that is located in the MPA, cover about 80 percent of the cost and the remaining 20 percent comes from government subsidies. ${ }^{1}$ Tourists visiting the MPA purchase their boat tickets through tourism companies.

\footnotetext{
${ }^{1}$ Source of numbers: Nha Trang Bay Marine Protected Area Authority.
} 
Included in the ticket price is an MPA user fee for swimming or diving, which the tourism company transfers to the government for funding the MPA.

The aim of the paper is to elicit national tourists' willingness to pay (WTP) a price premium for boat trips within the MPA using a discrete choice experiment (DCE) survey of Vietnamese tourists visiting the NTB MPA. The motivation given for the price premium is improvements in the environmental quality and increased biodiversity within the MPA, which result from an expansion of the MPA. So far, the application of DCEs to MPAs have been concerned with estimating benefits of environmental goods such as biodiversity, coral cover, endangered species, environmental quality and habitat values (Boxall et al. 2012; Can \& Alp 2012; Madani et al. 2013; Stefanski \& Shimshack 2015; Schuhmann et al. 2013). To our knowledge, so far no valuation study has included social factors such as unemployment of local fishermen that are affected by environmental improvements in an MPA.

DCE studies of environmental issues on land have considered this factor and show that respondents reaction to local unemployment is somewhat ambiguous. ${ }^{2}$ Some studies show a positive WTP to maintain rural employment (Birol \& Cox 2007; Morrison 2002; Morrison et al. 1999; Othman et al. 2004), while others show that people do not care about employment effects of a policy change (Adamowicz et al. 1998). As the NTB MPA provides jobs for a significant number of local fishers who live on the islands within the MPA, a loss of their livelihoods may be a consequence of restoring the environmental quality of the MPA. It is therefore relevant to include both social and environmental variables in the survey.

Our results show that tourists are willing to pay, on average, a substantial price premium on the current ticket price for a large increase in environmental quality. Environmental quality is by far the most important factor to national tourists and is larger by an order of magnitude compared to, for example, coral cover. Furthermore, we find that people are almost indifferent

\footnotetext{
${ }^{2}$ Local unemployment is also denoted non-use value of employment (Bennett and Blamey, 1999)
} 
towards employment effects and that WTP to avoid job-loss is very small. Looking at the welfare effects of simulated management scenarios we find that the benefits generated for improved biodiversity restoration and environmental quality are sufficient to cover the management costs.

The rest of the paper is organized as follows: section two presents a description of the NTB MPA, section three presents survey design, sampling, and model specification. Section four presents the results of the study and discussion of those results, section five presents the management implications and the last section contains conclusions.

\section{Study Area}

Nha Trang city is located on the coast in the central part of Vietnam. NTB covers approximately $507 \mathrm{~km}^{2}$ and is a hub of marine biodiversity, marine aquaculture, commercial fishing, tourism, and shipping. The biodiversity in NTB is the highest in Vietnamese coastal waters (Tuan et al. 2002) and it is relatively high for the overall Pacific Ocean (Van Nguyen \& Phan 2008) with 350 species of hard coral (accounting for over $40 \%$ of all reef-building coral species in the world), 220 species of demersal fish, 160 species of mollusks, 18 species of echinoderms, and 62 species of algae and seagrass. This marine area is considered a major nursery ground supplying fish larvae to other Vietnamese waters and possibly also to Cambodian waters (Dung 2009).

An assessment in 2002 indicated that marine biodiversity in NTB had declined substantially (Tuan et al. 2002). Coral reefs and some commercial fish stocks were in poor condition, and many species had become locally extinct due to human activities such as overfishing, aquaculture, tourism and urban run-off (Dung 2009). Recognizing the importance of biodiversity in NTB and the increasing pressures on marine resources, the government established the first MPA in Vietnam here in 2002 (initially named Hon Mun MPA and later 
changed to NTB MPA) with a total protected area of $160 \mathrm{~km}^{2}$ consisting of nine islands and their surrounding waters (Figure 1). The MPA is regulated into three zones with different levels of use and protection (Tuan et al. 2002). First are the core zones (red color) with an area of 16 $\mathrm{km}^{2}$, stretching from the water's edge out to 300 meters, including four islands with the highest biodiversity, and allowing tourism only. Second are the buffer zones (yellow color) from the core zones' border out to 300 meters and/or 300 meters from the water's edge of the remaining islands. Traditional fishing gears, marine aquaculture and tourism are allowed in these areas, but no trawling. Third are the transition zones (light blue color), open to all activities but including limitations on bottom trawl with regard to mesh size and engine power.

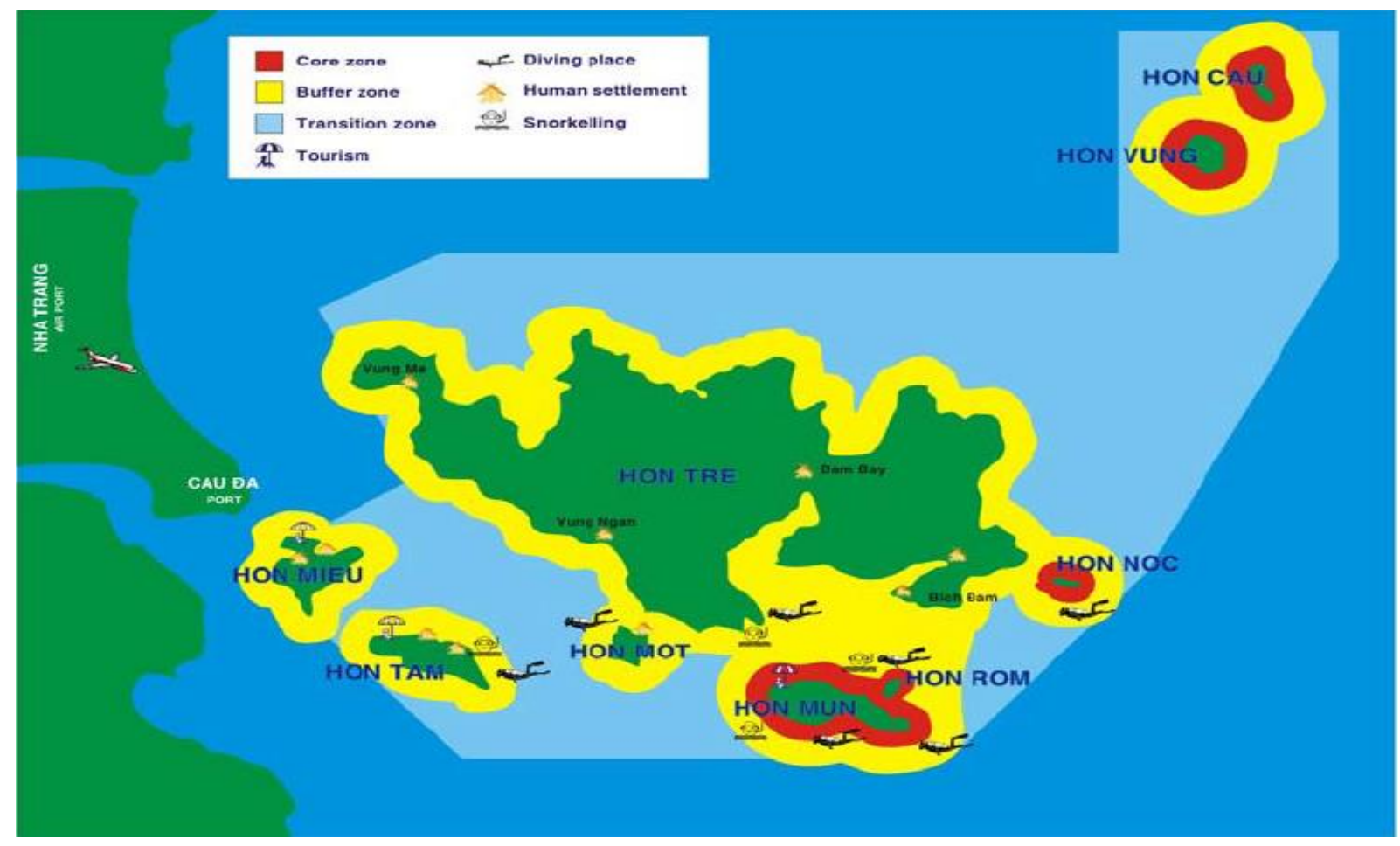

Figure 1. The location of NTB MPA. Source: Tuan et al. 2002

Although the NTB MPA was established with the main purpose of biodiversity conservation, it failed to achieve this goal (Tuan 2011). Two main reasons have been suggested are: i) unplanned and unregulated human activities within the MPA have increased the pressure on local resources, and ii) the regulated core zones are too narrow to ensure biodiversity restoration and prevent marine environmental pollution (Dung 2009). Expanding the core zone and 
changing management policy may improve marine biodiversity, coral reef cover and coastal environmental quality. However, the financing for sustaining and running the NTB MPA is indicated to be one of the greatest challenges (Dung 2009) and expanding the core zone of the MPA is expected to increase management costs.

Initial funding for establishing and running the NTB MPA was provided for four years by the Global Environment Fund through the World Bank, the Danish International Development Agency, the International Union for Conservation of Nature (IUCN), and the Government of Vietnam. At the end of 2005, external funding by donations came to a halt (Thu et al. 2005). Since then income from user fees levied on tourists when visiting the Mun islands, the core zone with the richest biodiversity, has provided the main funding for running the NTB MPA. One possible way to cover the additional management costs is to increase the boat trip ticket price for tourists taking the sea/islands tour within the MPA. The managers' challenge is to explore whether there is WTP increased fees among the visitors and determine the size of this potential increase.

\section{Survey Design and Model Specification}

\subsection{Survey Design}

The good to be valued in this DCE is a hypothetical core zone expansion of the NTB MPA. Following a literature review and focus group discussions, four attributes and their levels were determined. These were coral cover, environmental quality, fishermen's job losses and ticket price. The attribute live hard coral cover represents one type of biodiversity in the NTB MPA. Expanding the core zones in the MPA is a strategy to increase biodiversity in general as well as the abundance and species of coral in particular. Halpern (2003) showed that on average, creating a reserve may over a period of time double density, triple biomass, and raise organism size and diversity by 20 - $30 \%$ relative to an unprotected area. 
The change in coral cover is indicated to have positive impact on tourists' utility (Parsons \& Thur 2008; Schuhmann et al. 2013). The coral cover attribute has three levels; an average of 13\% live hard coral cover was recorded in the last assessment (Tuan et al., 2005) and this is taken as the status quo (SQ) attribute level. 20\% and 30\% are two alternative levels for this attribute after 10 years of core zone expansion. ${ }^{3}$

Phu et al. (2013) show that tourists are usually very concerned about the environmental quality within the NTB MPA, and in particular waste and seascape disturbance. Tourists can see the solid waste everywhere from the dock where they await their tour boats, along the edge of the islands, on the islands, and/or on the seabed where they scuba dive and snorkel. ${ }^{4}$ The presence of floating plastic bottles belonging to seed lobster traps and floating aquaculture cages which tourists can see when they are on the boat trips, are believed to reduce the scenic view. Hence, the coastal environmental quality in terms of visible waste and seascape disturbance is included as an attribute. This attribute takes three levels: low, medium, and high quality with low quality also considered as the SQ level.

Job loss of the fishermen is the last non-cost attribute in the design. The re-zoning scheme of the NTB MPA, as discussed above, may have short-run unemployment effects for the local fishermen. Vietnamese tourists visiting the MPA may be concerned about these effects when

\footnotetext{
${ }^{3}$ The assumed levels of coral cover are based on NTB biological indicators as follows. Firstly, before 1994, the average coral cover in the NTB was recorded to be $30 \%$ (Ben et al. 2015). Secondly, coral cover in the core zone - Mun island has increased by $50 \%$ after 4 years of protection (Tuan et al. 2005). Thirdly, coral reefs are distributed mostly along the coast and around the islands within the NTB MPA (Tuan et al. 2005), of which, some places not located in the current MPA core zone, have high quality reef habitats. If the expansion of the core zone takes place in these sites, this may promise a quick increase in coral cover.

${ }^{4}$ About ten tons of solid waste are discharged into the NTB MPA daily (Anon, 2015). Although solid waste collection efforts are made, they are inefficient because the waste is distributed throughout the MPA by sea currents and pushed again by tides onto the beaches.
} 
they make choices regarding the alternatives of the MPA management plan. About 1,100 households live on the islands within the MPA, of which $80 \%$ are fishermen, and $75 \%$ of them engage in fishing near shore around these islands (Van 2013). Assuming that a maximum of $30 \%$ of existing near shore fishermen would lose their job, the levels of the job loss attribute are set to be $0,50,100$, and 200 , where 0 is the SQ-level.

Finally, the payment vehicle is a price premium for boat trip tickets within the MPA, which takes four levels: 20, 50, 100, and 200 thousand Vietnamese Dong (VND). ${ }^{5}$ Respondents were told that the added revenue from the increased ticket price will accrue to a marine environmental fund that will be used to cover management costs for increased biodiversity and improved environmental quality in the NTB MPA. Table 1 presents the attributes and their levels.

Table 1. Attributes and levels used for the DCE.

\begin{tabular}{|c|c|c|c|c|}
\hline Attribute & Coral cover & $\begin{array}{c}\text { Environmental } \\
\text { quality }\end{array}$ & Job loss & Cost \\
\hline Variable name & Coral & Environment & Job loss & Cost \\
\hline Description & The average & Visible waste & The number of & Increase in ticket \\
& cover of live & and floating & lost jobs for & frice of \\
& hard coral & traps/cages & fishermen & sea/islands tour \\
& within the MPA & within the MPA & & (1000 VND) \\
\hline Status quo (SQ) & $13 \%$ & Low & 0 & 50 \\
\hline Level 1 & $20 \%$ & Low & 0 & 100 \\
\hline Level 2 & $30 \%$ & Medium & 50 & 200 \\
\hline Level 3 & & High & 100 & \\
\hline Level 4 & & & & \\
\hline
\end{tabular}

\footnotetext{
${ }^{5}$ The exchange currency in 2015 is $1 \mathrm{USD}=22,547$ VND (The State Bank of Vietnam, www.sbv.gov.vn/)
} 
The four attributes and their levels constitute 96 possible combinations. Based on parameters obtained from two pilots, an efficient design for a multinomial logit model was developed. The design assumed attribute level balance and was constructed using the D-efficiency criterion, aiming at generating parameter estimates with as small standard errors as possible (Scarpa \& Rose 2008). The D-efficiency design produced 12 choice sets, which were in turn randomly blocked into two different questionnaire versions (6 choice sets per block). An example of a choice card is presented in Table 2 .

Table 2. Example of the choice card.

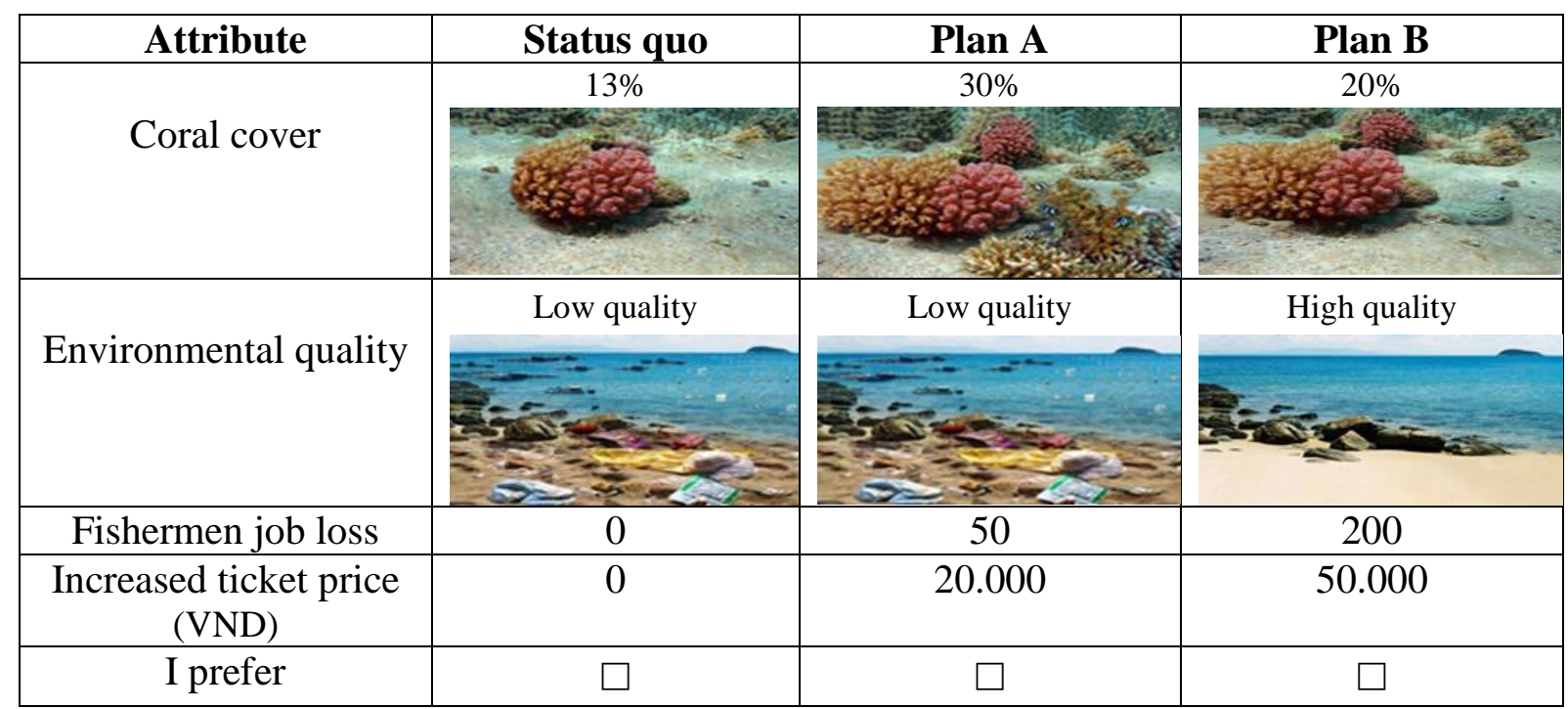

\subsection{Model specification}

\subsubsection{Mixed logit model}

The analysis of discrete choice data is based on the random utility model. This model assumes that a person's utility from choosing a specific alternative is described by one systematic and one random component. The former is a function of observed variables while the latter includes all unobserved variables, which impact on the utility of choosing a specific alternative. Hence, utility can be expressed as; 


$$
U_{n i t}=\beta_{n} x_{n i t}+\varepsilon_{n i t}
$$

where, $U_{\text {nit }}$ is the utility of individual $n$ obtained from choosing alternative $i$ in choice situation $t, x_{n i t}$ is a vector of observed attributes of alternative $i, \beta_{n}$ is a vector of random parameters, and $\varepsilon_{\text {nit }}$ is a random component of the utility of alternative $i$ and is assumed to be independent and identically distributed (iid) following a type 1 extreme value distribution.

Because we assume heterogeneous preferences, the model parameters are not fixed across the population and are weighted following a pre-specified distribution. Let the vector of random parameters be denoted as:

$$
\beta_{n}=\beta+\Gamma \eta_{n}
$$

where $\beta$ is a vector of population means of the parameters, $\Gamma$ is the lower Cholesky matrix with standard deviations on the diagonal and $\eta_{n}$ is a draw from a specified distribution, often the normal or log-normal. We allow for preference correlation by letting the off-diagonal elements of $\Gamma$ be non-zero.

We use the mixed logit model (MXL) to estimate national tourists' preferences for increasing biodiversity, environmental quality and loss of fishers' jobs within the NTB MPA. The benefit of the MXL is that it allows the modeling of heterogeneous preferences across respondents and correlated parameters. Tourists who like seeing coral might also prefer high coastal environmental quality, thus the coefficients of coral cover and environmental quality attributes may be correlated. Similarly, tourists who have preferences for good environmental conditions might prefer a reduction of the number of fishermen within the MPA.

The mixed logit probability of the sequence of choices made by a respondent is the integral over the product of the logit formula for all possible values of $\beta$

$$
\operatorname{Pr}\left(i_{n} \mid x_{n}\right)=\int \prod_{t=1}^{T} \frac{\exp \left(\mu \beta_{n}^{\prime} x_{n i t}\right)}{\sum_{j \in C} \exp \left(\mu \beta_{n}^{\prime} x_{n j t}\right)} f(\beta) d \beta
$$


where $\mu$ is a scale parameter that is typically set equal to one and is inversely proportional to the standard deviation of the error terms, and $f(\beta)$ is a density function. The integral does not have a closed-form solution and is approximated through simulation (Hensher et al. 2005). Aggregating over all respondents yields the likelihood function, and for ease of estimation one normally estimates the parameters by maximizing the log of the likelihood function (Train 2009).

\subsubsection{Measurements of unconditional WTP and Welfare}

The results from a DCE model can be used for deriving the marginal attribute WTPs to determine the amount of money individuals are willing to pay in order to get some benefit from the implementation of a project or new policy, and the change in consumer surplus $(\triangle C S)$ resulting from this project or change of policy (Train, 2009).

Unconditional mean WTPs are calculated as the ratio of the parameter estimates of a non-cost attribute and the cost attribute, ceteris paribus.

$$
W T P_{k}=-\frac{\beta_{k}}{\beta_{c}}
$$

where $\beta_{k}$ and $\beta_{c}$ are the estimates for $X_{k}$ (non-cost attribute) and $X_{c}$ (cost attribute) respectively. The change in consumer surplus is calculated as the change in utility (in monetary terms) that a person receives in the new management scenario compared to the current situation.

$$
\Delta C S=-\frac{1}{\beta_{c}}\left[\ln \left(\sum_{j \in C} \exp \left(V_{n j t}^{1}\right)\right)-\ln \left(\sum_{j \in C} \exp \left(V_{n j t}^{0}\right)\right)\right]
$$

where the superscripts 0 and 1 refer to the current situation and a new management scenario, respectively.

\subsection{Sampling}


The DCE survey was administered in April 2015 during the weekends. Face-to-face interviews were conducted with a convenience sample of 150 Vietnamese visitors (not including two pilot groups) participating in boat island tours within the NTB MPA. Each respondent answered six choice cards. They were asked to choose their most preferred alternative, and were told that there were no right or wrong answers. The respondents were also told that reasons for increasing the ticket price was, amongst others, to raise funds for the environmental improvement of the MPA. In order to reduce hypothetical bias the questionnaire contained a cheap-talk script to remind respondents of their budget constraint (Cummings \& Taylor, 1999; Carlsson et al., 2005). It also included questions regarding socio-demographic variables and attitudes towards environmental protection in general. ${ }^{6}$

Sample characteristics are given in Table 3. The sample has a higher male share (61\%) compared to the national average $(49.5 \%)$. This is because when we requested a family to answer the questionnaire in most cases a man was the representative. Only $5 \%$ of respondents are above 50 years of age while the official national recorded number is $17 \%$. The reason may be that very few older tourists wanted to answer the questionnaire because they cannot read or had forgotten their glasses, or they allowed their accompanying children to answer the questionnaire. The official average education at undergraduate level was $7.3 \%$ in 2014 , while it is $73 \%$ of sample in this study. ${ }^{7}$ The average income of the respondents is about 300 USD/month, but we do not have data on average income levels of the population for a comparison. The surveyed sample in this study is Vietnamese tourists visiting the NTB MPA, which may have different characteristics to the Vietnamese population in general.

Table 3. Descriptive statistics for respondents, $\mathrm{n}=150$.

\section{Characteristics}

\footnotetext{
${ }^{6}$ The questionnaire is available from the corresponding author upon request.

${ }^{7}$ Reported by General Statistic Office of Vietnam (GSO). https://gso.gov.vn/Default_en.aspx?tabid=491
} 


\begin{tabular}{|c|c|c|}
\hline $\begin{array}{l}\text { Gender } \\
\text { Male } \\
\text { Female }\end{array}$ & $\begin{array}{l}92 \\
58\end{array}$ & $\begin{array}{l}61 \\
39\end{array}$ \\
\hline $\begin{array}{l}\text { Age } \\
\qquad \begin{array}{l}19-30 \text { years } \\
31-50 \text { years } \\
51 \text { years and above }\end{array}\end{array}$ & $\begin{array}{c}87 \\
55 \\
8\end{array}$ & $\begin{array}{c}58 \\
37 \\
5\end{array}$ \\
\hline $\begin{array}{l}\text { Marital status } \\
\text { Single } \\
\text { Married }\end{array}$ & $\begin{array}{l}62 \\
88\end{array}$ & $\begin{array}{l}41 \\
59\end{array}$ \\
\hline $\begin{array}{l}\text { Education } \\
\text { High school or below } \\
\text { Undergraduate } \\
\text { Graduate }\end{array}$ & $\begin{array}{c}23 \\
109 \\
17\end{array}$ & $\begin{array}{l}15 \\
73 \\
11\end{array}$ \\
\hline $\begin{array}{l}\text { Occupation } \\
\text { Labourer } \\
\text { Others }\end{array}$ & $\begin{array}{l}92 \\
58\end{array}$ & $\begin{array}{l}61 \\
39\end{array}$ \\
\hline $\begin{array}{l}\text { Individual income per month (USD) } \\
\quad<178 \\
\quad 178-356 \\
>356\end{array}$ & $\begin{array}{l}30 \\
76 \\
38\end{array}$ & $\begin{array}{l}20 \\
51 \\
25\end{array}$ \\
\hline $\begin{array}{l}\text { Residence } \\
\text { Ha Noi } \\
\text { Da Nang } \\
\text { Ho Chi Minh } \\
\text { Others }\end{array}$ & $\begin{array}{c}21 \\
7 \\
52 \\
70\end{array}$ & $\begin{array}{c}14 \\
5 \\
35 \\
47\end{array}$ \\
\hline
\end{tabular}

\section{Results and Discussion}

\subsection{Model Estimates}

We use two models to estimate Vietnamese tourists' willingness to pay for restoring the environmental quality of NTB MPA. The first model is a standard mixed logit model and the second is a mixed logit model with correlated parameters. Both models are estimated in R using the "gmnl"-package (Sarrias \& Daziano 2015) and 1000 standard Halton draws.

The job loss attribute is a measure of social cost, so it is reasonable to argue that people have negative marginal utility for this attribute and thus assume this attribute to be log-normally distributed. However, it is also possible to argue that tourists have positive preferences for the job loss attribute for two reasons. First, if tourists believe that floating juvenile lobster traps destroying the MPA seascape are the consequences of fishermen's activities, they may like to 
reduce the number of fishermen in order to have a more attractive seascape. Second, if tourists believe that resources are overexploited and fishermen are putting pressure on fish stocks and destroying coral due to their extraction of dead coral for making lobster traps, they may like to reduce the number of fishers in order to conserve coral and limit the fishing pressure. We therefore choose a normal distribution for the job loss random parameter. We let estimated parameters of coral cover and environmental attributes follow a normal distribution, and keep the cost attribute parameter fixed. In this study, having a fixed cost parameter makes marginal WTP follow a normal distribution, and we avoid extreme WTP values associated with e.g. a log-normally distributed cost coefficient. ${ }^{8}$ We let the environmental attribute enter the model using a dummy specification

The estimated results of the two models are reported in Table 4. The model accounting for correlation across random parameters gives the better fit. The two MXL models give statistically significant standard deviations for all attributes, indicating that the data supports preference heterogeneity across respondents for these attributes. The signs and statistical significance of all attribute coefficients in the two models are consistent, except for a change in the sign of the mean estimate of the job loss attribute in the MXL model with correlation. It is however still insignificant.

Table 4. Model estimate results (standard errors in parentheses).

\begin{tabular}{|l|l|l|}
\hline \multirow{2}{*}{} & \multicolumn{2}{|c|}{ MXL } \\
\cline { 2 - 3 } & without correlation & with correlation \\
\hline
\end{tabular}

\footnotetext{
8 While choosing a fixed price coefficient is an established practice when analysing discrete choice data, it does imply that all respondents have the same marginal utility of that attribute. We did run models where cost followed a log-normal distribution with sign change - another common choice. Such a distribution has behavioural appeal because it secures that all respondents have a negative marginal utility of price. However, this distribution was not well suited for our data. A large proportion of our respondents were predicted to have marginal utility of price close to zero. Combined with the unbounded nature of the chosen distributions this led to very large and behaviourally implausible estimates of willingness-to-pay. Using a fixed price, while behaviourally restrictive, does provide us with a negative marginal utility of price and well behaved willingness-to-pay functions.
} 


\begin{tabular}{|l|l|l|}
\hline Fixed parameters & $-0.004(0.002)^{* * *}$ & $-0.005(0.002)^{* *}$ \\
cost & & \\
Random parameters & $0.065(0.015)^{* * *}$ & $0.111(0.018)^{* * *}$ \\
coral & $0.080(0.012)^{* * *}$ & $0.093(0.015)^{* * *}$ \\
med.env & $0.939(0.143)^{* * *}$ & $1.134(0.188)^{* * *}$ \\
med.env_SD & $0.950(0.202)^{* * *}$ & $1.587(0.209)^{* * *}$ \\
high.env & $1.648(0.228)^{* * *}$ & $2.052(0.307)^{* * *}$ \\
high.env_SD & $1.090(0.238)^{* * *}$ & $2.258(0.334)^{* * *}$ \\
job loss & $-0.00001(0.0008)$ & $0.0007(0.0009)$ \\
job loss_SD & $0.006(0.001)^{* * *}$ & $0.006(0.001)^{* * *}$ \\
Likelihood ratio index & & \\
Log-likelihood at convergence & 0.126 & 0.171 \\
Number of observations & -855.22 & -804.64 \\
Number of parameters estimated & 900 & 900 \\
AIC & 9 & 15 \\
Likelihood ratio test & 1728.45 & 1639.28 \\
\hline
\end{tabular}

Note: 1) med.env = medium environmental quality, high.env = high environmental quality; 2) The numbers are the mean values of normally distributed parameters of the attributes; 3) SD: standard deviations of the same distribution; 4$) * \mathrm{p}<0.05 ; * * \mathrm{p}<0.01 ; * * * \mathrm{p}<0.001$.

Table 5. Correlations matrix (upper triangular) and Cholesky matrix (lower triangular and diagonal) - standard error in parentheses.

\begin{tabular}{|l|rrrr|}
\hline & coral & med.env & high.env & job loss \\
\hline Coral & $0.0929(0.015)$ & 0.8383 & 0.8360 & 0.0369 \\
med.env & $1.3305(0.265)$ & $-0.8653(0.300)$ & 0.9979 & -0.0610 \\
high.env & $1.8877(0.389)$ & $-1.2307(0.370)$ & $-0.1449(0.314)$ & -0.1242 \\
job loss & $0.0002(0.001)$ & $0.0009(0.002)$ & $0.0058(0.001)$ & $-0.0003(0.004)$ \\
\hline
\end{tabular}

Because the output of the MXL model with correlation gives a better fit, we will report the results from this model. Given the assumption of normally distributed variables, the means and the standard deviations of coral and high.env imply that $88 \%$ and $82 \%$ of the sampled population, respectively, have a positive value for the coral cover and high environmental 
quality. There are also indications of strong positive correlations among taste intensities for coral cover and environmental quality (see Table 5, upper triangular), implying that an individual, who cares about the corals and would like to see an increase in coral cover, also cares about improvement in environmental quality.

The insignificant estimated mean value of the job loss random parameter indicates that on average tourists do not care about fishermen losing their jobs, but the standard deviation is statistically significant, suggesting that tourists have heterogeneous preferences with regard to this attribute. In particular, $45 \%$ of the respondents want to avoid unemployment for fishermen with the remaining having a positive utility of job loss. This can be better understood in light of survey results of national tourists visiting the NTB MPA carried out by Phu et al. (2013). They show that tourists believe that catching lobster juveniles has negative environmental effects, such as creating waste (93\% of the sample), destroying coral reefs and seascape (92\% and $89 \%$ of the sample) and depleting the lobster stock (69\% of the sample). Given these results, it is likely that some tourists would prefer to reduce the number of fishermen within the MPA. Looking at the lower Cholesky matrix (Table 5, lower triangular and diagonal) we see that the significant standard deviation for the job loss parameter is caused by cross-product correlations between job loss and high.env. This implies that the respondents who are more sensitive to the change in environmental quality, from low to high, are likely to have higher (positive) marginal utility of fishermen losing their jobs.

The overall fit of the MXL model with correlation is low by conventional standards used to describe probabilistic discrete choice models. However, there are still many studies in the environmental valuation literature having Pseudo- $\mathrm{R}^{2}$ less than 0.2 (Birol et al. 2006; Cerda et al. 2013; Othman et al. 2004), so this result is not uncommon. In addition, the chosen attributes in this study, except for job loss, are highly significant factors in the choice of an MPA management scenario. 


\subsection{Unconditional WTP and Welfare calculation}

The unconditional marginal WTPs and the changes in CS are calculated using the results of the MXL model with correlation. ${ }^{9}$ Table 6 shows that, the simulated mean marginal WTP is highest for the environmental attribute, while it is smaller for increases in coral cover and insignificant for fishermen's job loss. These estimates indicate that visitors are willing to pay a small amount for an increase in live hard coral cover, and much more for an improvement in the environmental quality. In other words, Vietnamese tourists are far more concerned about environmental quality within the MPA than about the coral cover and job loss for fishermen. Our findings are in concert with other valuation studies of protected areas on land, indicating that respondents from outside a region usually have a positive value for biodiversity and environmental quality attributes (Cerda et al. 2013) but care less about social attributes, such as local employment effects (Adamowicz et al., 1998).

Table 6. WTP estimates generated by the MXL model with correlation (USD/trip/person)

\begin{tabular}{|l|r|r|r|r|}
\hline Attribute & $2.5 \%$ quantile & \multicolumn{1}{|c|}{ Median } & \multicolumn{1}{|c|}{ Mean } & 97.5\% quantile \\
\hline Coral & 0.667 & 0.973 & 0.988 & 1.975 \\
med.env & 5.731 & 9.956 & 10.272 & 24.107 \\
high.env & 11.807 & 17.956 & 18.418 & 39.021 \\
job loss & -0.008 & 0.006 & 0.007 & 0.034 \\
\hline
\end{tabular}

There are reasonable explanations for the dominance of the environmental attribute. From the survey design we are looking at relatively small changes in coral cover (from $13 \%$ today to a

\footnotetext{
${ }^{9}$ The unconditional marginal WTPs and the changes in CS are the simulated estimates using 150,000 draws, which corresponds to 1000 draws per individual.
} 
maximum of $30 \%$ ), but large changes in environmental quality (low quality with lots of visible waste and seascape disturbance to a situation with no visible waste and nice sea-view). In addition, tourists can see the solid waste everywhere within the MPA together with the floating plastic bottles of the seed lobster traps and floating aquaculture cages over the sea surface. The beauty of coral reefs is, however, only visible to the tourists who are actually diving or snorkeling, and these account for only $2 \%$ of the total number of national tourists visiting the MPA. ${ }^{10}$ Hence, the visual presentation of the environmental attribute in the choice cards as well as the visible waste presented many places in the NTB probably have a strong influence on tourists' choices in comparison to the coral attribute.

In Table 7, we present the simulated estimates of the change in consumer surplus ( $\Delta \mathrm{CS})$ for twelve possible management scenarios relative to the current situation. As expected, $\Delta \mathrm{CS}$ increases as we move to management scenarios with improved environmental conditions. All scenarios with low environmental quality have low $\Delta \mathrm{CS}$ (between 0.4 and $1.6 \mathrm{USD}$ ), whereas the $\Delta \mathrm{CS}$ for all scenarios with high environmental quality is substantial (between 18 and 20 USD). Hence, the single most important attribute that affects the tourists' welfare is environmental quality, while the change in coral cover and fishermen's job loss are both of minor importance. This matches the fact that despite current waste collection efforts, solid waste is still among the most serious issues in the NTB MPA (Anon 2011; Anon 2014; Anon 2015; Anon 2013; Anon 2009). In addition, Vietnamese tourists visiting the NTB express that they are very concerned with regard to the environmental quality at the NTB MPA (Phu et al. 2013).

Table 7. New management scenarios and their changes in welfare, using the MXL model with correlation

\footnotetext{
${ }^{10}$ Nha Trang Bay Marine Protected Area Authority.
} 


\begin{tabular}{|c|c|c|c|c|c|c|c|}
\hline \multirow[t]{2}{*}{ Scenario } & \multicolumn{3}{|c|}{ Attributes } & \multicolumn{4}{|c|}{$\Delta \mathrm{CS}$ (USD/trip/person) } \\
\hline & $\begin{array}{l}\text { Coral } \\
\text { cover }\end{array}$ & $\begin{array}{c}\text { Environmental } \\
\text { quality }\end{array}$ & $\begin{array}{l}\text { Job } \\
\text { loss }\end{array}$ & $\begin{array}{c}2.5 \% \\
\text { quantile }\end{array}$ & Median & Mean & $\begin{array}{l}97.5 \% \\
\text { quantile }\end{array}$ \\
\hline SQ & $13 \%$ & Low & 0 & 0 & 0 & 0 & 0 \\
\hline Scenario 1 & $20 \%$ & Low & 50 & -0.336 & 0.373 & 0.415 & 1.809 \\
\hline Scenario 2 & $20 \%$ & Low & 100 & -0.734 & 0.679 & 0.761 & 3.505 \\
\hline Scenario 3 & $20 \%$ & Low & 200 & -1.532 & 1.292 & 1.453 & 6.879 \\
\hline Scenario 4 & $20 \%$ & High & 50 & 11.992 & 18.321 & 18.833 & 40.600 \\
\hline Scenario 5 & $20 \%$ & High & 100 & 12.086 & 18.627 & 19.179 & 42.049 \\
\hline Scenario 6 & $20 \%$ & High & 200 & 12.134 & 19.228 & 19.871 & 44.221 \\
\hline Scenario 7 & $30 \%$ & Low & 50 & -0.244 & 0.472 & 0.514 & 1.999 \\
\hline Scenario 8 & $30 \%$ & Low & 100 & -0.644 & 0.777 & 0.860 & 3.658 \\
\hline Scenario 9 & $30 \%$ & Low & 200 & -1.442 & 1.386 & 1.551 & 7.073 \\
\hline Scenario 10 & $30 \%$ & High & 50 & 12.063 & 18.417 & 18.932 & 40.809 \\
\hline Scenario 11 & $30 \%$ & High & 100 & 12.158 & 18.722 & 19.278 & 42.216 \\
\hline Scenario 12 & $30 \%$ & High & 200 & 12.204 & 19.322 & 19.970 & 44.396 \\
\hline
\end{tabular}

\section{Management Implications}

Ten years after the establishment of the NTB MPA, it has failed to achieve the main goal of biodiversity restoration (Tuan 2011). While many factors contribute to this failure, it is believed that lack of funding for management is the most important (Dung 2009; Van 2013). In this paper, we use a valuation survey to test whether national tourists are willing to pay a price premium for visiting the MPA, when the premium should contribute to cover costs of biodiversity restoration and improved environmental quality. The results show a positive 
willingness to pay to contribute to restoration of the environmental quality of the MPA. The question remains whether this WTP is sufficient to cover restoration costs?

The total price premium for national tourists can be calculated by multiplying the per unit change in consumer surplus $(\Delta \mathrm{CS})$ (see Table 7) with the number of national tourists visiting the NTB MPA. The number of national tourists visiting NTB MPA was about 500,000 annually in the period of $2010-2014 .{ }^{11}$ One must, however, take into consideration reduced demand from national tourists if a new management strategy that implies higher boat trip ticket price is implemented. On the other hand, better environmental conditions may attract new tourists. As we do not have any data on price-elasticities for this type of service, we are not able to estimate changes in demand due to a change in boat ticket price within the MPA.

In recent years, the annual management costs for the NTB MPA have been approximately USD 0.15 million. In addition, the new management scenarios suggested in our survey will increase the costs of managing the NTB MPA, but we do not have any estimate of the cost-increase required for the improvements. However, one reference of relevance is the total costs for establishing and operating the NTB MPA in the initial four years of the project (from 2002 to 2005), which was about 2 million dollars (Nam \& Herman 2005), which means on average USD 0.5 million per year. We use Scenario 12 in Table 7 as an example to calculate the total $\Delta \mathrm{CS}$ and to have a comparison to these management costs. If we assume that that an increase in ticket price does not affect demand, with 500,000 annual visitors, the expected $\Delta$ CS is USD 9.985 million. Using the 2.5 and 97.5 percentiles of the distribution yields the lower- and upperbound estimates, which are USD 6.1 million and USD 22.198 million, respectively. These estimated values are off the same magnitude as the above-mentioned costs.

A sensitivity analysis, assuming that the number of tourists drop by 90 percent to 50,000 national tourists, shows that the average $\Delta$ CS is USD 0.999 million, with lower- and upper-

\footnotetext{
11 Nha Trang Bay Marine Protected Area Authority.
} 
bound values of USD 0.61 million and USD 2.22 million. Even if we use the lower-bound mean estimate of USD 0.61 million, the $\triangle \mathrm{CS}$ is four times as high as the current management costs of USD 0.15 million and also higher than the initial funding of the project of USD 0.5 million per year. This result indicates that it is economically viable to implement alternative management scenarios, which secure high environmental quality in the NTB MPA.

These results do have policy implications. First, we find that respondents have strong preferences for environmental quality. This suggests that policy makers should, at the outset, focus on policies to address issues related to environmental quality. While we are careful not to make policy prescriptions, a few potential programs could be explored. Effective means of collecting and disposing of waste could prove beneficial. In addition, the presence of juvenile lobster fishery and aquaculture is indicated to have negative effects on both coral reef habitats and environmental quality, through extracting dead corals for making lobster traps, destroying scenery with floating aquaculture cages and juvenile lobster traps, and directly discharging into the sea bed the waste from aquaculture activities (Phu et al. 2013). Therefore, policies aimed at regulating these activities may not only increase tourists' utility through reducing solid waste and give more attractive sea views, but also reduce pressure on coral beds.

We also find evidence that there is a strong correlation between preferences for better environmental quality and increased coral cover. Hence, expanding the NTB MPA core zone in combination with some regulations and policies on environmental protection within the MPA would not only increase tourists' utilities but also contribute to biodiversity conservation and sustainable tourism development. It goes without saying, that any new policy implemented within the MPA must be accompanied by proper systems for monitoring and enforcement. This study indicates that there may well be possibilities to fund such increases in management cost via a price premium on the ticket price. 
Beside unemployment effects there are alternative negative short-term effects of the MPA core zone expansion on local fishermen such as reduced catches and increased fishing costs. Therefore, to soften the negative short-term impacts of this management policy on local fishermen, the increased income from tourism related to the MPA may be used partly to secure livelihoods for those who are most negatively affected. For example, local fishermen could be compensated for losing their jobs or avoiding specific areas under a 'payment for environmental services' scheme as suggested by Schuhmann et al. (2013). Moreover, they could also receive support for alternative income generation as was carried out in the initial the NTB MPA project, i.e. organize relevant courses to provide knowledge and skills for alternative livelihoods such as handicrafts, animal husbandry, tourism service and trading, and give financial support programs connected with these activities (Thu et al. 2005).

\section{Conclusions}

The aim of this study is to use a DCE to derive national tourists' WTP for seeing biodiversity restored and environmental quality improved in the NTB MPA in Vietnam. Based on marginal WTP for selected attributes, the change in consumer surplus for national tourists visiting the MPA can be calculated. Applying estimates on change in consumer surplus and costs of management scenarios, managers can assess whether it is economically viable to implement new management scenarios. The results of this paper show that although there are heterogeneous preferences across respondents for environmental attributes connected to the MPA, on average there is positive and significant WTP for improving coral cover and environmental quality. Estimation of change in consumer surplus and restoration costs suggests that management scenarios focusing on improving environmental quality within the NTB MPA are economically profitable. 
Our findings add to the empirical evidence suggesting that environmental protection and biodiversity conservation is not only good ecological policy, but viable economic policy as well. In addition, our findings also show that the tourism values of an MPA may be provided by both the ecological attributes (i.e. coral cover and environmental quality) and the social attribute (i.e. employment opportunities or losses), where the former is normally presented in the literature of MPA valuation while the latter is not.

The survey focused solely on national tourists, while international tourists constitute $23 \% .^{12}$ Future research should include both groups of tourists. Changes in the NTB MPA management policies could increase benefits not only to tourists, but to other stakeholders as well (e.g. fishermen, fisheries-based aquaculture, tourism operators, research and education, etc.). This study, however, discusses only economic benefits from tourism and the operating costs of the MPA. Future research should also include various stakeholders' preferences with regards to the changes in MPA management policies to provide a more comprehensive picture in order to efficiently achieve common goals of fishery management, conservation, research, education and tourism development. Also, a full benefit-cost analysis is necessary for more fully informed decision-making regarding new management strategies.

\section{Acknowledgments}

We would like to thank Claire Armstrong for good comments to the earlier versions of the paper, thanks to Vondolia Godwin Kofi, Ngoc Quach Thi Khanh for valuable inputs to earlier versions of the questionnaires, and thanks to the colleagues at the Nha Trang University for data collection. Bui Bich Xuan acknowledges funding from NORAD through the project NOMA-FAME (NOMAPRO-2006/10029). Erlend Dancke Sandorf acknowledges funding

\footnotetext{
${ }^{12}$ The share of international tourists is calculated from the tourism statistical data of Khanh Hoa Province (http://www.nhatrang-travel.com/index.php?cat=3003).
} 
from the Jan Wallander and Tom Hedelius foundation, and the Tore Browaldh foundation grant no. B2015-0490:1.

\section{References}

Adamowicz, W. et al., 1998. Stated preference approaches for measuring passive use values: choice experiments and contingent valuation. American Journal of Agricultural Economics, 80(1), pp.64-75.

Alban, F. et al., 2008. Economic analysis of Marine Protected Areas. A literature review. EMPAFISH Project Booklet, 3.

Anon, 2014. Environmental Pollution in Nha Trang Bay: Need the Synchronized Solutions. In Vietnamese Nguy cơ ô nhiễm vịnh Nha Trang: Cần có giải pháp đồng bộ. Khanh Hoa News, http://www.

Anon, 2015. Khanh Hoa: “Emergency” Marine Environment. In Vietnamese: Khánh Hòa: “Cấp cứu” môi trường biển. Environment and Resource Electronic Journal, http://bao. Anon, 2011. Polluted Nha Trang Bay. In Vietnamese: Vịnh Nha Trang bị ô nhiễm. Worker Electronic Journal, http://nld.

Anon, 2009. Protect the Coastal Environment in Nha Trang Bay. In Vietnamese: Nỗ lực bảo vệ môi trường biển vịnh Nha Trang. Seafood Reseach Institute, http://vov.

Anon, 2013. Waste in Nha Trang Bay. In Vietnamese: Vịnh Nha Trang hứng chất thải. Woker Electronic Journal, http://nld.

Ben, H. et al., 2015. The status, tendency, and ability to recover coral biodiversity in the Nha Trang Bay. In Vietnamse: Hiện trạng, xu thế và khả năng phục hồi đa dạng sinh học rạn san hô ở vịnh Nha Trang. Institute of Oceanography, Vietnam Academy of Science and 
Technoloy, 21(2), pp.176-187.

Birol, E. \& Cox, V., 2007. Using choice experiments to design wetland management programmes: The case of Severn Estuary Wetland, UK. Journal of Environmental Planning and Management, 50(3), pp.363-380.

Birol, E., Karousakis, K. \& Koundouri, P., 2006. Using a choice experiment to account for preference heterogeneity in wetland attributes: the case of Cheimaditida wetland in Greece. Ecological Economics, 60(1), pp.145-156.

Bosetti, V. \& Pearce, D., 2003. A study of environmental conflict: the economic value of Grey Seals in southwest England. Biodiversity and Conservation, 12(12), pp.2361-2392. Boxall, P.C. et al., 2012. Analysis of the economic benefits associated with the recovery of threatened marine mammal species in the Canadian St. Lawrence Estuary. Marine Policy, 36(1), pp.189-197. Available at: http://dx.doi.org/10.1016/j.marpol.2011.05.003.

Can, Ö. \& Alp, E., 2012. Valuation of environmental improvements in a specially protected marine area: A choice experiment approach in Göcek Bay, Turkey. Science of the Total Environment, 439, pp.291-298.

Cerda, C., Ponce, A. \& Zappi, M., 2013. Using choice experiments to understand public demand for the conservation of nature: a case study in a protected area of Chile. Journal for Nature Conservation, 21(3), pp.143-153.

Cummings, R. G., \& Taylor, L.O., 1999. Unbiased Value Estimates for Environmental Goods : A Cheap Talk Design for the Contingent Valuation Method. The American Economic Review, 89(3), pp.649-665.

Depondt, F. \& Green, E., 2006. Diving user fees and the financial sustainability of marine protected areas: Opportunities and impediments. Ocean and Coastal Management, 49(34), pp.188-202.

Dung, L.D., 2009. Nha Trang Bay marine protected area, Vietnam: Initial trends in coral 
structure and some preliminary linkages between these trends and human activities (2002-2005). Aquatic Ecosystem Health \& Management, 12(3), pp.249-257.

Halpern, B.S., 2003. The impact of marine reserves: do reserves work and does reserve size matter? Ecological Applications, 13(1), pp.117-137.

Halpern, B.S., Lester, S.E. \& Kellner, J.B., 2009. Spillover from marine reserves and the replenishment of fished stocks. Environmental Conservation, 36(4), pp.268-276.

Hensher, D.A., Rose, J.M. \& Greene, W.H., 2005. Applied choice analysis: a primer, Cambridge University Press.

Jacobsen, J.B. \& Thorsen, B.J., 2010. Preferences for site and environmental functions when selecting forthcoming national parks. Ecological Economics, 69(7), pp.1532-1544.

Juffe-Bignoli, D. et al., 2014. Protected Planet Report 2014, Cambridge, UK: UNEP-WCMC. Available at: http://wdpa.s3.amazonaws.com/WPC2014/protected_planet_report.pdf.

Lee, J.-H. \& Iwasa, Y., 2011. Tourists and traditional divers in a common fishing ground. Ecological Economics, 70(12), pp.2350-2360.

Madani, S., Martinez-Cruz, A.L. \& McConnell, K.E., 2013. Conservation Value of Coral Reefs around Kish Island, Iran. Marine Resource Economics, 28(4), pp.331-343.

Milazzo, M. et al., 2002. The Impact of Human Recreational Activities in Marine Protected Areas : What Lessons Should Be Learnt in the Mediterranean Sea? Marine Ecology, 23(1), pp.280-290.

Morrison, M., 2002. Understanding local community preferences for wetland quality. Ecological Management \& Restoration, 3(2), pp.127-134.

Morrison, M., Bennett, J. \& Blamey, R., 1999. Valuing improved wetland quality using choice modeling. Water Resources Research, 35(9), pp.2805-2814.

Nam, P.K. \& HERMAN, C., 2005. Financial sustainability of the Hon Mun Marine Protected Area. Lessons for other marine parks in Vietnam. University of Economics, Ho Chi Minh 
City.

Ngoc, Q.T.K. \& Flaaten, O., 2010. Protected areas for conflict resolution and management of recreational and commercial fisheries. Marine Resource Economics, 25(4), pp.409-426.

Othman, J., Bennett, J. \& Blamey, R., 2004. Environmental values and resource management options: a choice modelling experience in Malaysia. Environment and Development Economics, 9(6), pp.803-824.

Parsons, G.R. \& Thur, S.M., 2008. Valuing changes in the quality of coral reef ecosystems: a stated preference study of SCUBA diving in the Bonaire National Marine Park. Environmental and Resource Economics, 40(4), pp.593-608.

Phu, T.D. et al., 2013. Assessing the impact of the juvenile lobster fishery to the landscape, environment and marine resources in Nha Trang Bay. In Vietnamese: Đánh giá tác động của nghề khai thác tôm hùm giống đến cảnh quan môi trường và nguồn lợi thủy sản vịnh Nha Trang. Đề tài Khoa Học Công nghệ. Trương Đại học Nha Trang., In English.

Sanchirico, J.N. et al., 2005. No-take zones as optimal fishery management. Ecological Applications, 16, pp.1643-1659.

Sanchirico, J.N. et al., 2006. When are no-take zones an economically optimal fishery management strategy? Ecological Applications, 16(5), pp.1643-1659.

Sanchirico, J.N. \& Wilen, J.E., 2001. A bioeconomic model of marine reserve creation. Journal of Environmental Economics and Management, 42(3), pp.257-276.

Sarrias, M. \& Daziano, R.A., 2015. Multinomial Logit Models with Continuous and Discrete Individual Heterogeneity in R: The gmnl Package.

Scarpa, R. \& Rose, J.M., 2008. Design efficiency for non-market valuation with choice modelling: how to measure it, what to report and why*. Australian Journal of Agricultural and Resource Economics, 52(3), pp.253-282.

Schnier, K.., 2005a. Biological "hot spots" and their effect on optimal bioeconomic marine 
reserve formation. Ecological Economics, 52(4), pp.453-468.

Schnier, K.., 2005b. Revisiting biological "hot spots" and marine reserve formation. Ecological Economics, 54(1), pp.111-113.

Schuhmann, P.W. et al., 2013. Recreational SCUBA divers' willingness to pay for marine biodiversity in Barbados. Journal of environmental management, 121, pp.29-36.

Stefanski, S. \& Shimshack, J.P., 2015. Valuing Marine Biodiversity in the Gulf of Mexico: Evidence from the Proposed Boundary Expansion of the Flower Garden Banks National Marine Sanctuary. Marine Resource Economics, 31(2), pp.211-232.

Thu, H.V.T. et al., 2005. Socio-economic impact assessment of the Hon Mun MPA project on local communities within the MPA. Hon Mun Authority, Nha Trang, p.54.

Train, K.E., 2009. Discrete choice methods with simulation, Cambridge university press.

Tuan, V.. et al., 2005. Marine and Coastal Habitats of Nha Trang Bay Marine Protected Area, Khanh Hoa , Viet Nam: Reassessment 2002 - 2005. Biodiversity Report No 13, (13).

Tuan, V.S., 2011. Biodiversity Dynamics of Coral Reef in Nha Trang Bay and Management Measures. In Vietnamses: Biến động đa dạng sinh học rạn san hô vịnh Nha Trang và các giải pháp quản lý. Proceeding of 5th National Marine Science and Technology, pp.2939.

Tuan, V.S. et al., 2002. Marine and Coastal Habitats of Hon Mun Marine Protected Area, Nha Trang Bay, Vietnam Baseline Survey, March-April 2002. Hon Mun Marine Protected Area Pilot Project Biodiversity Technical Report, 5.

Van, D.H., 2013. Solutions to improve the management of the exploitation and protection of fisheries resources in Nha Trang Bay Marine Protected Area. In Vietnamese: Giải pháp nâng cao hiệu quả công tác quản lý khai thác và bảo vệ nguồn lợi thủy sản trong khu bảo tồn biển.

Wallmo, K. \& Edwards, S.F., 2008. Estimating non-market values of marine protected areas: 
a latent class modeling approach. Marine Resource Economics, 23(3). 